\title{
Estudios prequirúrgicos: Costos y consecuencias de su práctica
}

\author{
Rullán Corna NF. ${ }^{1,2}$, Grancelli S. ${ }^{1}$, Mangiavillano Á. ${ }^{1}$, Cambas L. ${ }^{1}$, Cuis Taccari M. ${ }^{1}$, Pintos E. ${ }^{1}$, \\ Martínez A. ${ }^{1}$, Iribarren C. ${ }^{1}$ \\ 1 Hospital Militar Central, CABA, Argentina. \\ 2 Hospital Universitario Cemic, CABA, Argentina.
}

Introducción: La valoración preoperatoria está consensuada como un elemento fundamental en el tratamiento multidisciplinario de cualquier patología quirúrgica. Bajo esta prerrogativa se diseñaron un conjunto de consensos para normatizar la indicación de estudios según el cuadro clínico del paciente y el riesgo inherente al procedimiento. La baja adhesión a los mismos trae diversas consecuencias tales como el retraso en la programación de las intervenciones, aumento del costo para el sistema de salud y hallazgos clínicos de implicancia patológica poco clara.

Métodos: Se cuantificó la totalidad de los pacientes valorados por el servicio de Evaluación Preoperatoria del Hospital Militar Central en el primer semestre del año 2019 (01 de enero 30 de junio inclusive), y se lo relacionó con la totalidad de los pacientes intervenidos en el mismo período de tiempo. En segunda instancia se identificó cuáles de los pacientes que fueron evaluados según el Score de ASA como 1 o 2 en consultorio habían concurrido con estudios que, en función de las guías, no eran necesarios para su intervención. Por último, se calculó en función de los costos para el sistema de salud del hospital, el monto total de los estudios prescindibles.

Resultados: Sobre un total de 3.203 casos intervenidos en el primer semestre de 2019, sólo 512 pacientes acudieron previamente a la consulta; el 15,98\% de los casos. De esos 512 pacientes, el 65,03\% (333 pacientes) fue definido según los evaluadores como un score de ASA 1 o 2, pudiendo prescindir de uno o más de los estudios indicados de forma reglada por los médicos tratantes (ECG - Laboratorio Completo - Placa de Tórax). Las implicancias económicas de ésta decisión se traduce en una pérdida para el sistema de salud de al menos 5.091 pesos argentinos (U\$S 116 aproximadamente) per cápita que, de mantenerse la proporción en el total de la muestra, nos sugiere una erogación de 1.057.289 pesos argentinos (USS 24.128 dólares).

Conclusiones: El sistema hospitalario no ha logrado gestionar de forma eficaz y eficiente tanto la concurrencia de los pacientes a la evaluación prequirúrgica, como la indicación de estudios previos, traduciéndose esto en la subvaloración de los pacientes de riesgo y la excesiva en los pacientes de bajo riesgo, redundando esto en una elevación del costo en salud y una demora en la asignación de los turnos quirúrgicos.

https://doi.org/10.25237/congresoclasa2019.104 